\title{
Formação em tempos de pandemia: análise das atividades formativas desenvolvidas pelos cursos presenciais de Serviço Social no ano de 2020*
}

Training in pandemic times: analysis of training activities developed by classroom courses in social work in 2020

\author{
Larissa Dahmer Pereira** \\ Andreza Telles*** \\ Gabriella de Souza Lopes****
}

\begin{abstract}
Resumo - O artigo apresenta resultados parciais do projeto de pesquisa intitulado Ensino superior e cursos de Serviço Social no Brasil: monitoramento e análise do processo de expansão, perfil profissional e propostas curriculares, que se voltou para o acompanhamento da formação, no período da pandemia do coronavírus, em cursos presenciais de Serviço Social, públicos e privados. Justifica-se tendo em vista a tendência de crescente movimento de ampliação de matrículas em cursos de EaD e, por sua vez, uma clara retração nas matrículas em cursos presenciais privados de Serviço Social, o que se aprofundou com a pandemia. Quanto aos procedimentos metodológicos, foram enviados formulários às coordenações de cursos de graduação presenciais de Serviço Social, públicos e privados, em todo o país. Buscou-se apreender quais atividades formativas foram (ou não) desenvolvidas nos dois períodos letivos de 2020 e quais as estratégias desenvol-
\end{abstract}

\footnotetext{
* Agradecemos desde já à docente Sabrina Pereira Paiva, que muito contribuiu na leitura atenta e crítica ao formulário de pesquisa. Também às/aos coordenadoras/es de cursos presenciais de Serviço Social que, em meio à exaustão do período, nos retornaram generosamente o formulário de pesquisa; e também às coordenações regionais da Abepss e aos Cress que nos auxiliaram no contato com diversas coordenações de curso.

Esse texto é dedicado, com muita tristeza, aos mais de 450 mil mortos (maio de 2021) em decorrência da Covid-19 e do (des)governo, despreparo e negacionismo de nossos governantes, dos quais nos tornamos, enquanto nação, reféns.

O presente texto foi redigido pela docente Larissa Dahmer Pereira. A mestra Andreza Telles e a bolsista de IC Gabriella de Souza Lopes realizaram o fundamental trabalho de contato, atualizações de dados e envio dos formulários aos sujeitos da pesquisa, sob a orientação da docente Larissa Dahmer Pereira, além das trocas e conversas frutíferas para a produção do presente trabalho.

** Docente da Escola de Serviço Social da UFF. Doutora em Serviço Social (UFRJ) e pós-doutora em educação (UFRJ). Pesquisadora e docente do Programa de Pós-Graduação em Serviço Social e Desenvolvimento Regional da UFF. Pesquisadora do CNPQ, bolsista em produtividade nível 2. Coordenadora do Núcleo de Pesquisa e Extensão sobre Trabalho, Educação e Serviço Social (Teia). E-mail: larissadahmerpereira@gmail.com. ORCID: https://orcid.org/00000002-4449-8184.

*** Assistente social (UFF) e mestre pelo Programa de Pós-Graduação em Serviço Social e Desenvolvimento Regional da UFF. Pesquisadora do Teia. Bolsista TCT da Faperj. E-mail: andreza.telles@gmail.com. ORCID: https://orcid.org/ 0000-0003-2767-7356.

**** Graduanda em Serviço Social pela UFF. Bolsista de Iniciação Científica Pibic/CNPq. Pesquisadora do Teia. Email: gabriellal@id.uff.br. ORCID:https://orcid.org/0000-0002-1277-9053.
} 
vidas para a consecução das mesmas. Salienta-se que os resultados apresentados no presente artigo são parciais, dado que a pesquisa permanece em curso e acompanhando o que vem ocorrendo na formação em tempos de pandemia. Desse modo, trata-se aqui da apresentação de um primeiro momento da pesquisa, mas que nos traz achados interessantes para pensar a formação, seus desafios e limites no delicado momento que vivenciamos.

Palavras-chave: ensino superior brasileiro; formação em Serviço Social; pandemia Covid-19.

\begin{abstract}
This article presents partial results of a research project entitled "Higher education and social work courses in Brazil: monitoring and analysis of the expansion process, professional profile, and curricular proposals", recently focusing on the monitoring of training in public and private on-campus undergraduate programs in social work, during the COVID-19 pandemic. Such research is justified in view of the growing trend of increasing enrollment in distance education courses and, in turn, a clear retraction in enrollment in private faceto-face social work courses, which deepened with the pandemic. As for the methodological procedures, forms were sent to program coordinations of on-campus undergraduate programs in social work, in public and private institutions throughout the country. We sought to learn, through the responses of the program coordinators, which training activities were (or were not) developed in the two academic terms of 2020 and which strategies were developed to achieve them. It should be noted that the results provided in this article are partial, given that the research is ongoing and following what has been occurring in training in pandemic times. Thus, this is the presentation of a first step of the research, but it already brings us interesting findings to reflect on the formation in social work, its challenges and limits in the delicate moment that we are experiencing.
\end{abstract}

Keywords: Brazilian higher education; training in social work; COVID-19 pandemic

\title{
Introdução
}

O ano de 2020 nos marcou, mundialmente, pela pandemia do coronavírus. O desconhecimento da doença, a velocidade de transmissão e o agravamento e morte de um número significativo de pessoas somam-se à forma irresponsável e intencional, por parte do governo federal brasileiro, de enfrentamento da doença por meio de um método absolutamente questionável: a denominada "imunidade de rebanho". A negação da gravidade da doença, a lentidão em tomar decisões em nível nacional quanto à compra de insumos e vacinas, a postura do presidente Bolsonaro de não só negar a doença, mas sobretudo de fomentar aglomerações, negar o uso de máscaras e, ainda, de naturalizar as mortes de inúmeros brasileiros/as, nos fazem desgraçadamente olhar para o decorrer de 2021 (estamos em março de 2021, no pior momento da pandemia até hoje vivenciado no país) sem muita esperança. 
A pandemia assolou o mundo e, no caso da particularidade brasileira, aguçou nossas mazelas, dificuldades e profundas desigualdades sociais. Com uma economia afundando, agravou-se o empobrecimento e o desemprego da população brasileira, além de o sistema de saúde estar vivenciando o auge do colapso, sendo a área da educação também uma das que sofreu (e sofre) brutalmente os impactos da pandemia. Na educação básica, numerosos já são os estudos e alertas sobre o aumento do fosso social relativo ao acesso à educação por parte de crianças e adolescentes. A "opção" do ensino remoto torna-se, frente à brutal e histórica desigualdade social brasileira, literalmente remota para a maior parte das crianças e adolescentes das escolas públicas. ${ }^{1}$

No ensino superior também vivenciamos desigualdades imensas: somos o país com um dos sistemas de ensino superior mais privatizados do mundo, sendo tal nível, aqui, muito mais caracterizado como uma mercadoria do que propriamente um direito social. Além disso, as instituições de ensino superior (IES) são, no Brasil, majoritariamente instituições não universitárias, já conhecidas pela ausência do tripé ensino, pesquisa e extensão. Soma-se, ainda, a forte presença dos conglomerados empresariais que apostam no ensino superior como mais um nicho de lucratividade e, portanto, vêm investindo fortemente na robotização e no ensino a distância (EaD) como meios de "otimizar" os custos relativos a investimentos e, claro, maximizar a lucratividade. O perfil de expansão do ensino superior brasileiro é, pois, marcado pelo setor privado-mercantil, oligopolizado, vinculado ao setor financeiro e que aposta sobretudo em meios para maximização de lucros. Isso tudo traz fortes impactos para a formação dos profissionais certificados em tais IES, fragilizando sobremaneira a formação em todas as áreas.

A pandemia trouxe para o ensino superior a agudização do processo acima brevemente abordado: se a robotização do trabalho docente e o EaD, de forma geral, tornaram-se, no pós-1990 e especialmente após os anos 2000, estratégias cruciais para a expansão das matrículas e o fortalecimento do setor privado-mercantil, ${ }^{2} \mathrm{com}$ a pandemia tal processo acelerou-se em progressão geométrica.

Para áreas como a de Serviço Social, a pandemia aprofunda a tendência de manutenção e/ou ampliação de matrículas em cursos ofertados a distância; diminui substancialmente as matrículas em cursos privados presenciais; e traz sérias dificuldades para o processo formativo desenvolvido nos cursos públicos, com a introdução das atividades remotas. Em recente trabalho (PEREIRA, 2020), analisamos dados relativos às matrículas em cursos de Serviço Social no país, com o recorte temporal do início e fim de

\footnotetext{
${ }^{1}$ Sobre a histórica desigualdade educacional brasileira, relacionando-a com a desigualdade estrutural do país, ver texto de Sguissardi (2020).

${ }^{2}$ Para uma análise do EaD como estratégia de fortalecimento do setor privado-mercantil, ver coletânea organizada por Vale e Pereira (2019).
} 
cada governo federal (Fernando Henrique Cardoso - 1995 e 2002; Lula 2003 e 2010; Dilma - 2011 e 2016; Temer - 2018; Bolsonaro - 2019), e aqui apresentamos a tabela e o gráfico de forma atualizada, incluindo o primeiro ano do governo Bolsonaro.

Conforme é possível visualizar no gráfico, tanto os cursos privados presenciais como os ofertados a distância apresentaram retração nas matrículas, o que se relaciona com o contexto de forte crise, em todos os aspectos, vivenciada pelo país desde o ano de 2016. A crise econômica, sobretudo, afasta discentes do ensino superior privado. Destarte, alerta-se para o impacto muito mais forte nos cursos presenciais privados, que tiveram, entre 2018 e 2019, uma retração de $20 \%$ em suas matrículas, o que tende a se agravar com a pandemia. Os cursos ofertados a distância tiveram uma redução insignificante nas matrículas, de menos de $0,1 \%$. Já os cursos públicos mantiveram suas matrículas estáveis e, em 2019, apresentaram crescimento pífio $(1,1 \%)$. Salienta-se que não incluímos dados relativos ao período da pandemia (ano de 2020), visto que o Censo do Ensino Superior 2020 até o momento ainda não foi publicado.

\section{Tabela 1 - Matrículas em cursos de Serviço Social: privados presenciais, públicos presenciais e de EaD,} por ano de início/fim dos governos FHC, Lula, Dilma, Temer, Bolsonaro.

\begin{tabular}{|c|c|c|c|}
\hline Ano & $\begin{array}{c}\text { Matrículas em } \\
\text { cursos } \\
\text { presenciais } \\
\text { privados }\end{array}$ & $\begin{array}{c}\text { Matrículas em } \\
\text { cursos } \\
\text { presenciais } \\
\text { públicos }\end{array}$ & $\begin{array}{c}\text { Matrículas } \\
\text { em cursos EaD }\end{array}$ \\
\hline 1995 & 9.567 & 9.460 & 0 \\
\hline 2002 & 17.190 & 10.925 & 0 \\
\hline 2003 & 20.256 & 11.701 & $0^{3}$ \\
\hline 2010 & 52.848 & 15.876 & 74.474 \\
\hline 2011 & 54.710 & 17.309 & 80.650 \\
\hline 2016 & 50.753 & 17.883 & 96.055 \\
\hline 2018 & 35.271 & 17.271 & 86.447 \\
\hline 2019 & 28.024 & 17.454 & 86.391 \\
\hline
\end{tabular}

Fonte: Elaboração da autora. Sinopses Estatísticas da Educação Superior 1995, 2002, 2003, 2010,2011, 2016, 2018 e 2019 (INEP/MEC, 1995, 2002, 2003, 2010, 2011, 2016, 2018, 2019).

Após esse breve balanço relativo ao movimento de crescimento x retração de matrículas nos cursos presenciais, públicos, privados e de EaD na área do Serviço Social, apresentamos resultados parciais da pesquisa

\footnotetext{
${ }^{3}$ As matrículas em cursos ofertados a distância estão zeradas nos anos 1995, 2002 e 2003, porque nesse período ainda não havia curso de Serviço Social ofertado na referida modalidade.
} 


\section{Gráfico1 - Matrículas em cursos presenciais, públicos e EaD}

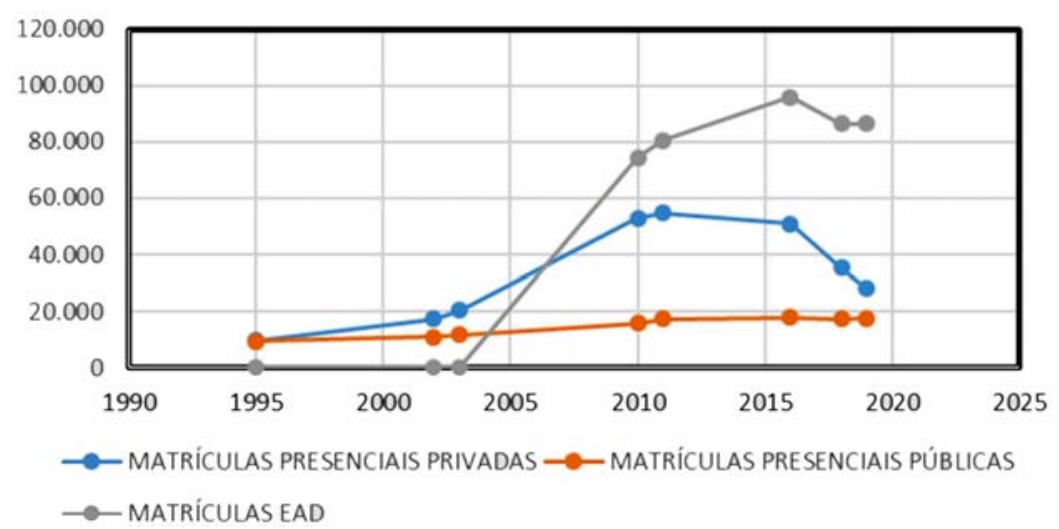

Fonte: Elaboração da autora. Sinopses Estatísticas da Educação Superior 1995, 2002, 2003, 2010, 2011, 2016, 2018 e 2019 (INEP/MEC, 1995, 2002, 2003, 2010, 2011, 2016, 2018, 2019).

atualmente em curso e desenvolvida no âmbito do Núcleo de Pesquisa e Extensão sobre Trabalho, Educação e Serviço Social (Teia). Parte do projeto de pesquisa, intitulado Ensino superior e cursos de Serviço Social no Brasil: monitoramento e análise do processo de expansão, perfil profissional e propostas curriculares, voltou-se para o acompanhamento da formação no período da pandemia do coronavírus em cursos presenciais de Serviço Social, públicos e privados.

Justifica-se tal pesquisa tendo em vista a tendência acima delineada: apreende-se o crescente movimento de ampliação de matrículas em cursos $\mathrm{EaD}$ e, por sua vez, uma clara retração nas matrículas em cursos presenciais privados de Serviço Social. Assim, com a pandemia, constatamos a necessidade de acompanhamento próximo de tal processo, visto que observamos como tendência a configuração futura de dois perfis profissionais radicalmente distintos: aqueles formados em cursos públicos e, portanto, mais próximos das Diretrizes Curriculares da Associação Brasileira de Ensino e Pesquisa em Serviço Social (Abepss) ${ }^{4}$ e, por outro lado, profissionais formados em cursos ofertados a distância, cuja formação obedece à lógica radicalmente distinta do que é propugnado pelo projeto formativo da Abepss. $^{5}$

Salienta-se que os resultados apresentados no presente artigo são parciais, dado que a pesquisa permanece em curso e acompanhando o

\footnotetext{
${ }^{4}$ Ver: Abepss (1996).

${ }^{5}$ Temos discutido, há alguns anos, a formação de perfis radicalmente distintos de profissionais, de acordo com o percurso formativo, seja em IES públicas, seja em IES privado-mercantis ou nas não mercantis. Para uma síntese coletiva do debate, ver coletânea recente organizada por Vale e Pereira (2019). O posicionamento das entidades da categoria também é claro, conforme CFESS/Abepss/Enesso (2010, 2014).
} 
que vem ocorrendo na formação em tempos de pandemia. Desse modo, trata-se aqui da apresentação de um primeiro momento da pesquisa, mas que nos traz achados interessantes para pensar a formação, seus desafios e limites no delicado momento que vivenciamos.

\section{Formação em Serviço Social em tempos de pandemia: a visão de coordenadores/as de curso sobre os limites e desafios do processo formativo}

A pesquisa apresentada no presente artigo, iniciada em setembro de 2020, objetivou conhecer, por meio do envio de formulários às coordenações de cursos, como os cursos de graduação presenciais de Serviço Social, públicos e privados, enfrentaram, no ano de 2020, o período da pandemia do coronavírus. Buscou-se apreender quais atividades formativas foram (ou não) desenvolvidas nos dois períodos letivos de 2020 e quais as estratégias desenvolvidas pelas coordenações de cursos desde março de 2020, quando foi decretada a pandemia pela OMS, para a consecução das mesmas. Compreende-se por atividades formativas a inserção de discentes em projetos de pesquisa, extensão e ensino (disciplinas, orientação de TCC, dentre outras).

O estudo foi dividido em duas etapas com duração de seis meses, de setembro de 2020 até março de 2021. Inicialmente, foi realizada uma atualização das planilhas, alimentadas com dados relativos aos cursos de Serviço Social inscritos no Cadastro Nacional de Cursos e Instituições de Educação Superior (e-MEC). Buscamos dados relativos aos cursos de graduação em Serviço Social privados e públicos na modalidade presencial das cinco regiões do Brasil. ${ }^{6}$

Na primeira fase da pesquisa foram coletados os contatos das coordenações de curso por meio dos sites das instituições de ensino superior (IES) e também via contato telefônico e/ou e-mail das instituições. Foi realizado, ainda, contato com a Abepss e com os Conselhos Regionais de Serviço Social (Cress) de todos os estados do país, com o objetivo de acessar os contatos das coordenações de curso, geralmente disponíveis junto às comissões de formação dos Cress. Cabe ressaltar que o processo de busca pelos contatos das coordenações de cursos e o envio dos e-mails foi constante durante todo o trabalho.

É importante destacar as dificuldades encontradas ao longo do processo de investigação. A primeira dificuldade relaciona-se com as informações pertinentes aos cursos de graduação em Serviço Social disponíveis na plataforma e-MEC. Identificou-se que estas não são fidedignas com a realidade de cada IES aqui pesquisada. Muitos cursos constam na plataforma

${ }^{6}$ A presente pesquisa não aborda os cursos ofertados a distância. 
e-MEC, por exemplo, com a situação "em funcionamento", mas, ao realizarmos contato com as IES, constatamos que o curso havia sido encerrado, inclusive antes de 2020 (da pandemia). Isto é, o curso permanece com a autorização para funcionar, mas efetivamente não está com turmas abertas. Após o contato com as IES, notamos que alguns cursos já estavam extintos, não estavam em funcionamento por falta de procura ou por não formação de turma no período, muitos cursos deixaram de ofertar a modalidade presencial e passaram a ser ofertados somente a distância. Desse modo, após a verificação de quais cursos presenciais estiveram efetivamente em funcionamento, durante o ano de 2020, definimos o universo pesquisado.

Portanto, apresentamos a seguir o quantitativo de cursos informados na plataforma e-Mec, aqueles em efetivo funcionamento no ano de 2020, o quantitativo de cursos com os quais conseguimos contato (telefônico e/ou e-mail) e, por fim, o quantitativo de cursos que nos retornou com a resposta ao formulário enviado por e-mail e dirigido às/aos coordenadoras/ es de cursos presenciais de Serviço Social.

\section{Tabela 2 - Quantitativo de cursos presenciais de Serviço Social na plataforma e-Mec; cursos em efetivo funcionamento; cursos contatados e cursos que retornaram a pesquisa.}

\begin{tabular}{|c|c|c|c|c|c|}
\hline Região & $\begin{array}{c}\text { Quantitativo } \\
\text { de cursos- } \\
\text { e-Mec }\end{array}$ & $\begin{array}{c}\text { Quantitativo } \\
\text { de cursos } \\
\text { contatados }^{8}\end{array}$ & $\begin{array}{c}\text { Quantitativo de } \\
\text { cursos em } \\
\text { efetivo } \\
\text { funcionamento } \\
\text { ano } 2020^{9}\end{array}$ & $\begin{array}{c}\text { Quantitativo } \\
\text { de cursos que } \\
\text { retornaram a } \\
\text { pesquisa }\end{array}$ & $\begin{array}{c}\% \text { de } \\
\text { retorno a } \\
\text { pesquisa }^{10}\end{array}$ \\
\hline Sul & 42 & 42 & 37 & 9 & $24,32 \%$ \\
\hline Sudeste & 192 & 133 & 133 & 35 & $26,31 \%$ \\
\hline Centro-Oeste & 32 & 36 & 29 & 3 & $10,34 \%$ \\
\hline Nordeste & 191 & 181 & 180 & 15 & $8,33 \%$ \\
\hline Norte & 40 & 35 & 34 & 12 & $35,29 \%$ \\
\hline
\end{tabular}

Fonte: Elaboração das autoras.

Ainda na primeira etapa do trabalho foi desenvolvido um formulário com questões, cujo objetivo é conhecer como os referidos cursos enfrentaram o período da pandemia do coronavírus. Isto é, por meio das respostas das/os coordenadoras/es dos curso (presenciais) de Serviço Social, buscamos apreender como foram (ou não) realizadas as atividades formativas

\footnotetext{
${ }^{7}$ Cursos de Serviço Social cadastrados na plataforma e-Mec. Buscamos em "consulta avançada", curso: Serviço Social; presencial; situação "em atividade"; cursos por Unidade Federativa.

${ }^{8}$ Os contatos foram realizados de diversas formas (e-mail, telefone, Whatsapp), com o objetivo de verificar se o curso funcionou no ano de 2020 e de solicitar o contato com o/a coordenador/a do curso em Serviço Social.

${ }^{9}$ Esse é o universo com o qual trabalhamos na pesquisa: isto é, os cursos com os quais conseguimos contato (com o curso e/ou a IES) e que verificamos o seu efetivo funcionamento no ano de 2020.

${ }^{10} \mathrm{O}$ percentual de retorno à pesquisa foi calculado em função dos cursos que estiveram em efetivo funcionamento no ano de 2020, conforme a 4⿳亠丷a coluna da Tabela 2: Quantitativo de cursos em efetivo funcionamento ano 2020.
} 
nos meses de março a dezembro de 2020. Quais foram as estratégias implementadas pelas coordenações de curso para que os cursos continuassem em funcionamento a partir de março de 2020, quando a OMS decretou o isolamento social como uma medida obrigatória e preventiva para conter a disseminação do coronavírus? Na segunda etapa do trabalho, o formulário foi dirigido às/aos coordenadoras/es dos cursos de graduação em Serviço Social por e-mail, o que ocorreu entre os meses de outubro de 2020 e março de 2021. Primeiramente foi enviado um e-mail apresentando a pesquisa e, ao mesmo tempo, buscou-se saber a disponibilidade e interesse de cada coordenação de curso em participar do presente estudo. Assim, mediante o aceite de participação na pesquisa - sendo garantido às/aos participantes o sigilo tanto em relação à identificação individual, quanto em relação às IES e cursos -, a cada retorno o formulário foi enviado para as coordenações de cursos.

Consideramos fundamental ressaltar que o contexto de realização da presente pesquisa é um momento em que os/as docentes/coordenadores/ as se encontram exauridos tanto emocional como fisicamente. Tal exaustão, em decorrência da pandemia e de todos os seus efeitos - dentre eles, o trabalho remoto e a sobrecarga de trabalho em todos os seus aspectos (doméstico, de cuidado com crianças e idosos, além do trabalho acadêmico remoto, extenuante) -, trouxe-nos limites relativos a um maior retorno dos cursos. Nesse sentido, destacamos que esse é um momento inicial da pesquisa e os resultados aqui apresentados são parciais, visto que os contatos com os cursos continuam e a pesquisa propõe-se a acompanhar como os cursos presenciais de Serviço Social, públicos e privados, estão enfrentando os desafios da formação em Serviço Social em um período tão crítico como o de uma pandemia.

- Dos 74 cursos respondentes, destaca-se a participação majoritária de cursos da Região Sudeste $(47,3 \%)$, seguida das regiões Nordeste $(18,9 \%)$, Norte $(17,6 \%)$, Sul $(10,8 \%)$ e Centro-Oeste $(5,4 \%)$.

- A maior parte dos cursos participantes encontra-se no interior do estado (58,1\%) e 41,9\% estão localizados nas capitais do país. - Dos cursos participantes, 32,4\% são cursos inseridos em IES públicas federais, seguidos de $29,7 \%$ de cursos inseridos em IES privadas com fins lucrativos; $24,3 \%$ são cursos em IES privadas sem fins lucrativos e 13,5\% são cursos em IES públicas estaduais. - A maior parte dos cursos participantes está inserida em IES universitárias, sendo $44,6 \%$ de cursos inseridos em IES públicas universitárias e $32,4 \%$ de cursos em IES privadas universitárias. Ou seja, essa inserção dos cursos respondentes em IES universitárias (públicas e privadas) nos alerta para a seguinte questão: como tais cursos desenvolveram atividades de ensino, pesquisa e extensão no período da pandemia? 
- Parte significativa dos cursos que participaram da pesquisa foi criada recentemente: 40,5\% entre os anos de 2003 e 2010, e $17,6 \%$ entre os anos de 2011 e 2016 . Tal dado talvez possa ser relacionado com a pergunta seguinte, sobre a filiação do curso à Abepss: 51,4\% afirma não ter filiação à Abepss, o que merece ser acompanhado pela entidade, visto o acirramento das dificuldades trazidas ao processo formativo em decorrência da pandemia e no pós-pandemia.

À pergunta "Após a declaração da Organização Mundial de Saúde (OMS), em 11 de março de 2020, sobre a pandemia mundial do coronavírus, o curso de Serviço Social realizou a seguinte ação em relação às atividades acadêmicas:", 47,3\% dos cursos responderam que suspenderam imediatamente as atividades formativas presenciais, enquanto que $43,2 \%$ dos cursos respondentes informaram que mantiveram as atividades formativas presenciais até decreto municipal/estadual/federal indicar a necessidade de paralisação das atividades presenciais, quando, então, suspenderam-se as atividades. ${ }^{11}$

Perguntados sobre "Caso o curso de Serviço Social tenha suspendido as atividades presenciais, indique as atividades formativas que passaram a ocorrer de forma remota", os cursos respondentes indicaram várias atividades, ${ }^{12}$ dentre elas, orientação de trabalho de conclusão de curso (TCC) $(83,8 \%) ; 68,9 \%$ dos cursos respondentes ofertou projetos de extensão (como cursos, palestras, seminários, dentre outras atividades em formato remoto); disciplinas obrigatórias abertas para alguns/todos os períodos (exceto Supervisão Acadêmica de Estágio) (74,3\%); bancas de TCC (60,8\%); grupos de pesquisa (iniciação científica), com 55,4\%; Supervisão Acadêmica de Estágio $(51,4 \%)$; disciplinas optativas abertas para alguns/todos os períodos $(43,2 \%)$; disciplinas (obrigatórias e/ou optativas) voltadas somente para os concluintes $(12,2 \%)$. Ou seja, os cursos mantiveram, no formato remoto, atividades de ensino (disciplinas, orientações de TCC, supervisão acadêmica de estágio), extensão e pesquisa.

Em relação ao aproveitamento dos/as discentes nas atividades remotas, as coordenações avaliaram que houve adesão e aproveitamento: medianos (40,5\%); satisfatórios (35,1\%); 14,9\% indicaram que essa avaliação ainda não foi feita no curso; 9,5\% consideraram a adesão e o aproveitamento discente insatisfatório. ${ }^{13}$

Sobre as dificuldades encontradas pelos/as discentes, as coordenações de curso indicaram como maior limite a dificuldade de acesso a equipamentos de informática (86,5\% dos respondentes); condições para

\footnotetext{
${ }^{11}$ Questão de múltipla escolha. Os demais, responderam "outros", configurando menos de $10 \%$ dos respondentes. ${ }^{12}$ Os respondentes puderam escolher várias opções, sem limitação. Portanto, a soma dos percentuais não encerra $100 \%$.

${ }^{13}$ Questão de múltipla escolha. Os demais responderam "outros", configurando menos de $10 \%$ dos respondentes.
} 
o acompanhamento das atividades remotas $(79,7 \%)$; diminuição de renda e/ou desemprego $(74,3 \%)$; sobrecarga de trabalho, doméstico e externo $(67,6 \%)$; falta de preparo para lidar com as TICs (63,5\%); adoecimento mental (58,1\%); crianças em idade escolar e sem aulas (43,2\%); adoecimento por Covid-19 (40,5\%); outras formas de adoecimento (27\%); o curso ainda não avaliou $(9,5 \%) .{ }^{14}$

Em relação às dificuldades encontradas pelo corpo docente, as coordenações assim as elencaram: ${ }^{15}$ sobrecarga de trabalho (doméstico e externo) $(79,7 \%)$; falta de preparo para lidar com as TICs (62,2\%); condições para o acompanhamento das atividades remotas (52,7\%); crianças em idade escolar e sem aulas (48,6\%); dificuldade de acesso a equipamentos de informática $(32,45 \%)$; adoecimento mental $(32,4 \%)$; outras formas de adoecimento (29,7\%); adoecimento por Covid-19 (21,6\%); diminuição de renda e/ou desemprego (14,9\%); o curso ainda não avaliou (8,1\%).

Após elencar as dificuldades enfrentadas por discentes e docentes, solicitamos que as coordenações indicassem as estratégias desenvolvidas para a consecução das atividades formativas. As coordenações indicaram as seguintes estratégias: ${ }^{16}$ apoio a discentes e docentes em situação de adoecimento mental, por Covid-19 e/ou outras formas de adoecimento (64,9\%); encaminhamento a políticas públicas/programas sociais e/ou inserção de discentes em programas sociais da IES (discentes com dificuldades financeiras) (50\%); diminuição das disciplinas ofertadas no semestre, tendo em vista a sobrecarga de trabalho advinda do isolamento social (40,5\%); abertura de editais para o acesso a equipamentos de informática (39,2\%); outros $(11,2 \%)$; o curso não desenvolveu, até o momento, nenhuma atividade formativa remota de ensino, mas permanece com atividades de pesquisa e extensão desenvolvidas pelos/as docentes remotamente $(4,1 \%)$.

Dentre aqueles/as que indicaram a opção "outros", 20 respondentes discorreram brevemente sobre as estratégias desenvolvidas pelas coordenações, aqui arroladas: i) diversificação do formato das disciplinas (lives, indicações de vídeos no YouTube, filmes); ii) flexibilização da presença e/ ou prazos; iii) projetos de extensão; iv) núcleo psicossocial da IES de apoio a docentes e discentes; v) oficinas de formação didático-pedagógica aos docentes para utilização de tecnologias para elaboração e execução das aulas; vi) discussões coletivas/colegiadas permanentes; vii) intensificação no atendimento individual e respeito às condições individuais; viii) questionário junto aos discentes, para conhecer o perfil e identificar demandas; ix) acompanhamento e busca ativa de alunos que tiveram frequência às aulas remotas interrompidas para encontrar alternativas de retorno; $x$ ) posi-

\footnotetext{
${ }^{14}$ Os respondentes puderam escolher várias opções, sem limitação. Portanto, a soma dos percentuais não encerra $100 \%$.

${ }^{15}$ Os respondentes puderam escolher várias opções, sem limitação. Portanto, a soma dos percentuais não encerra $100 \%$.

${ }^{16}$ Os respondentes puderam escolher várias opções, sem limitação. Portanto, a soma dos percentuais não encerra $100 \%$.
} 


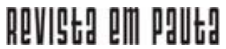

\} FORMAÇÃO EM TEMPOS DE PANDEMIA - PEREIRA, L. D.; TELLES, A.; LOPES, G. S. \}

DOI: $10.12957 /$ REP.2021.60307

cionamento contrário do departamento ao ensino remoto emergencial (ERE) obrigatório e avaliação constante junto a docentes e discentes; xi) abertura de contato direto com a coordenação e uso intensificado das redes sociais para melhoria da comunicação junto aos discentes; xii) aulas gravadas e contato constante com discentes por Whatsapp, teleconferência; xiii) disponibilização dos laboratórios de informática da IES para docentes e discentes.

Perguntados/as sobre se o corpo docente foi pressionado a desenvolver as atividades remotas, as coordenações assim responderam: ${ }^{17}$ para $45,9 \%$ houve pressão por parte da IES; para 45,9\% foi uma decisão coletiva/ colegiada; foi uma decisão deliberada pelo conjunto para $35,1 \%$; foi uma decisão da instituição empregadora para $32,4 \%$; houve pressão por parte dos discentes para $16,2 \%$.

Sobre o retorno às atividades presenciais - "A IES e/ou o curso retomarão as atividades presenciais antes da criação da vacina para o Covid19 ?" - as coordenações assim responderam: 36,5\% - "não, pois a decisão institucional é retornar somente após a vacinação"; 24,3\% - "não sei informar"; $13,5 \%$ - sim, a IES e o curso estão preparados para retornar no $1^{\text {o }}$ semestre de 2021. Os demais indicaram a opção "outros". ${ }^{18}$

A pergunta seguinte - "Após a pandemia, você considera que a IES e/ou o curso incluirão as atividades remotas como parte do trabalho docente e da formação dos/as discentes (como reuniões remotas, bancas remotas, aulas remotas, dentre outras)?" - nos revela que 43,2\% dos respondentes consideram que o curso e a IES incluirão as atividades remotas como parte da formação e, por sua vez, do trabalho docente; 29,7\% não souberam informar; enquanto que 13,5\% indicaram que não consideram que a IES e/ ou curso farão tal inclusão.

Por fim, solicitamos que as coordenações respondessem, de forma dissertativa: "como avalia, no curso que coordena, os impactos da pandemia para a formação profissional e a realização de atividades formativas remotas"? As respostas foram bastante ricas e buscamos agrupá-las de acordo com a proximidade de preocupações/apontamentos:

Questões relacionadas às disciplinas teórico-práticas:

- Estágios foram suspensos, dificuldades de alunos colarem grau. Campos com vagas suspensas. Dificuldade de abrir vagas no póspandemia será ainda maior.

- Prejuízos no desenvolvimento de disciplinas teórico-práticas (estágios, oficinas etc.). Afastamento presencial dos discentes dos espaços sócio-ocupacionais gera prejuízo à formação.

- Impossibilidade de realização de algumas atividades de pesquisa e/ou extensão, que demandam atividades de campo.

\footnotetext{
${ }_{17}$ Os respondentes puderam escolher várias opções, sem limitação. Portanto, a soma dos percentuais não encerra $100 \%$.

${ }^{18}$ Questão de múltipla escolha.
} 
Questões de ordem didático-pedagógica:

- Atividades remotas trazem limite quanto à relação dialógica desenvolvida nas disciplinas; dificuldades de ordem pedagógica, como o processo de avaliação (garantir a sua processualidade).

- Dificuldade de acesso às bibliografias.

- Dificuldade de conclusão dos ementários/conteúdos das disciplinas; redução da carga horária de aulas e dias de aulas.

- Desestímulo dos estudantes, baixa adesão, dificuldades dos discentes de lidarem com ensino remoto, falta de concentração nas aulas síncronas. Dificuldades de conciliar atividades síncronas e assíncronas. Aumento nos trancamentos e abandonos/evasão.

- Dificuldades maiores para os/as discentes que ingressaram na universidade no período da pandemia, por não estarem ambientados com a universidade.

Questões relacionadas ao trabalho docente:

- Dificuldade dos docentes no uso/manejo das TICs.

- Pandemia ampliou e intensificou a precarização do trabalho docente.

- Controle e vigilância do trabalho docente aumentaram, agora com gravações das aulas e uso de demais tecnologias.

Questões relacionadas à organização coletiva e às relações interpessoais: - Limitações quanto às mobilizações e organizações coletivas de docentes e discentes.

- Fragilidades nas relações interpessoais.

Questões relacionadas às condições sociais, econômicas e psíquicas de discentes e docentes:

- Dificuldade de conectividade dos discentes e/ou ausência de equipamento de informática; falta de espaço adequado e tempo para o desenvolvimento dos estudos. Necessidade de divisão de espaço e equipamento de informática com outras pessoas da casa (para trabalho e ensino remoto, a exemplo de crianças em idade escolar).

- Adoecimento (mental e físico) do corpo docente e discente; exaustão, ansiedade, estresse; isolamento social. Excesso de tempo nas telas. Condições ergonômicas inadequadas.

- Perda de renda e emprego das famílias, obrigando discentes a trabalhar.

- Dificuldades de docentes e discentes em conciliar demandas de estudo e trabalho com as demandas do ambiente doméstico. Ampliação das demandas relativas aos cuidados com idosos e crianças em idade escolar, aprofundando a desigualdade de gêne- 
ro. Abertura da vida/ambiente privado ao realizar atividades remotas.

- Maior dificuldade de acesso aos meios tecnológicos em virtude de ser pessoa com deficiência.

- Ampliação das desigualdades entre discentes no acesso ao ensino remoto.

- Discentes de origens camponesa, quilombola e indígena, que não fazem uso de meios tecnológicos, com menos possibilidades de acesso a esses meios.

Destaca-se, ainda, em relação ao universo pesquisado, os/as coordenadores/as que, ao final do formulário, apresentaram um balanço positivo e otimista no que diz respeito ao período de pandemia vivenciado pelos cursos e as respostas que deram em virtude dos desafios (im)postos: atividades colaborativas entre docentes e discentes; protagonismo discente nas atividades formativas; aprendizado e manejo das novas TICs (competências e habilidades tecnológicas); adaptabilidade ao "novo normal"; superação de desafios; e aperfeiçoamento de práticas educativas (metodologias ativas).

\section{À guisa de conclusão: alguns achados relativos aos limites e desafios da formação profissional em Serviço Social em tempos pandêmicos}

Conforme destacamos no início do artigo, a pesquisa ora apresentada encontra-se em curso e, infelizmente, constata-se que a pandemia, no Brasil especialmente, irá prolongar-se pelo ano de 2021, o que traz uma série de desafios à formação.

Os dados colhidos junto às coordenações de curso nos indicaram que a maioria dos cursos de Serviço Social, ainda que críticos em relação ao ensino remoto, desenvolveu atividades formativas diversas de ensino, pesquisa e extensão, compreendendo a importância da continuidade das atividades, da função social da universidade, mas com a clareza do profundo impacto desse modelo de ensino no processo formativo.

As disciplinas de caráter teórico-prático (oficinas e estágio supervisionado/supervisão acadêmica de estágio) são aquelas que mais trazem limitações e desafios, ao nosso ver, ao processo em curso. Com um horizonte de, pelo menos, dois anos em atividades remotas, visto a lentidão de vacinação, o surgimento de novas variantes e a ampliação do número de casos e mortes no Brasil (com o mês de março, após um ano de pandemia, sendo o pior momento desde o seu início no país), o estágio presencial torna-se um desafio e precisa ser discutido no âmbito da categoria e das unidades de ensino. Dois anos significam quatro semestres letivos, o que resulta praticamente em turmas formadas somente com a experiência do estágio 
remoto (para as unidades de ensino que liberaram tal atividade), trazendo implicações importantes para a formação desses/as futuros/as profissionais de Serviço Social.

Sobre os impactos da pandemia para a formação profissional, as coordenações de curso nos apontaram criticamente diversas e significativas questões: relacionadas às disciplinas teórico-práticas; de ordem didáticopedagógica; sobre o trabalho docente, organização coletiva, relações interpessoais; e, por fim, vinculadas às condições sociais, econômicas e psíquicas de discentes e docentes. Também obtivemos respostas, ainda que bastante diminutas, que olharam para o momento da pandemia como o de uma oportunidade, no sentido de novas aprendizagens e de aceitação de um "novo normal".

Algo que nos chamou a atenção foi que um percentual relevante de coordenações de curso avaliou que, após a pandemia, muitas atividades remotas passarão a fazer parte do cotidiano institucional, em um sistema híbrido (presencial e/ou a distância). Essa tendência tem sido acompanhada por nós e demonstrada no percentual de matrículas de cursos presenciais privados de Serviço Social, que ano a ano vêm decrescendo. Em sentido oposto, apreende-se o movimento crescente de matrículas (que são predominantes, inclusive) em cursos de Serviço Social ofertados na modalidade EaD, ao passo que os cursos públicos mantêm certa estabilidade. O hibridismo - acelerado em décadas com a pandemia - merece e precisa ser acompanhado por pesquisadores/as e entidades da categoria, com vistas a apreender quais serão os impactos no perfil de profissionais futuros e, por sua vez, quais as implicações de tal processo para o trabalho profissional.

Encerrando o artigo, gostaríamos de destacar duas colocações de coordenadores/as de curso: uma, que aborda as limitações do período pandêmico em diversos aspectos, e outra, que traz também as contradições do processo de implantação do ensino remoto, todas as suas dificuldades e implicações.

Foi um semestre limitado do ponto de vista pedagógico, solitário do ponto de vista institucional e adoecedor para docentes e discentes.

A realização de atividades formativas remotas impacta de forma contraditória a formação profissional. Por um lado, nos possibilita a manutenção de vínculos com as/os estudantes, a produção e troca de conhecimento, além de fortalecer o papel social da Úniversidade num contexto de pandemia, por meio de ações e pesquisa. Ao mesmo tempo, fragiliza a formação profissional, no sentido de não possibilitar de forma igualitária as condições de acesso e acompanhamento por parte de estudantes; ter a qualidade do ensino atravessada por condições objetivas e subjetivas que ultrapassam a competência docente; interfere na relação ensino-aprendizagem e impacta na integralização curricular, provocando ansiedade e angústia em parcela das/os estudantes. 


\section{Referências}

ABEPSS. Diretrizes gerais para o curso de Serviço Social. Rio de Janeiro, nov. 1996. Disponível em: http://www.abepss.org.br/arquivos/textos/docu mento_201603311138166377210.pdf. Acesso em: 5 fev. 2021.

CFESS/ABEPSS/ENESSO. Sobre a incompatibilidade entre graduação à distância e Serviço Social. Vol. 1. Brasília: CFESS/Cress/Abepss/Enesso, 2010. Disponível em http://www.cfess.org.br/arquivos/incompatibilidadevolume1 _2015-Site.pdf. Acesso em: 13 jan. 2021.

CFESS/ABEPSS/ENESSO. Sobre a incompatibilidade entre graduação à distância e Serviço Social. Vol. 2. Brasília: CFESS, 2014. Disponível em: http://www.cfess.org.br/arquivos/CFESS_incompatibilidadevolume2 _2014.pdf. Acesso em: 23 jan. 2021.

INEP/MEC. Sinopse estatística da educação superior 1995. Brasília: Inep/ MEC, 1995. Disponível em: https:/www.gov.br/inep/pt-br/areas-de-atuacao/ pesquisas-estatisticas-e indicadores/censo-da-educacao-superior. Acesso em: 12 jul. 2020.

INEP/MEC. Sinopse estatística da educação superior 2002. Brasília: Inep/ MEC, 2002. Disponível em: https://www.gov.br/inep/pt-br/areas-de-atuacao/ pesquisas-estatisticas-e indicadores/censo-da-educacao-superior. Acesso em: 12 jul. 2020.

INEP/MEC. Sinopse estatística da educação superior 2003. Brasília: Inep/ MEC, 2003. Disponível em: https://www.gov.br/inep/pt-br/areas-de-atuacao/ pesquisas-estatisticas-e indicadores/censo-da-educacao-superior. Acesso em: 12 jul. 2020.

INEP/MEC. Sinopse estatística da educação superior 2010. Brasília: Inep/ MEC, 2010. Disponível em: https://www.gov.br/inep/pt-br/areas-de-atuacao/ pesquisas-estatisticas-e indicadores/censo-da-educacao-superior. Acesso em: 12 jul. 2020.

INEP/MEC. Sinopse estatística da educação superior 2011. Brasília: Inep/ MEC, 2011. Disponível em: https://www.gov.br/inep/pt-br/areas-de-atuacao/ pesquisas-estatisticas-e indicadores/censo-da-educacao-superior. Acesso em: 12 jul. 2020.

INEP/MEC. Sinopse estatística da educação superior 2016. Brasília: Inep/ MEC, 2016. Disponível em: https://www.gov.br/inep/pt-br/areas-de-atuacao/ pesquisas-estatisticas-e indicadores/censo-da-educacao-superior. Acesso em: 12 jul. 2020.

INEP/MEC. Sinopse estatística da educação superior 2018. Brasília: Inep/ MEC, 2018. Disponível em: https:/www.gov.br/inep/pt-br/areas-de-atuacao/ 


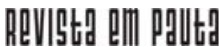

\} FORMAÇÃO EM TEMPOS DE PANDEMIA - PEREIRA, L. D.; TELLES, A.; LOPES, G. S. \}

DOI: 10.12957/REP.2021.60307

pesquisas-estatisticas-e indicadores/censo-da-educacao-superior. Acesso em: 12 jul. 2020.

INEP/MEC. Sinopse estatística da educação superior 2019. Brasília: Inep/ MEC, 2019. Disponível em: https:/www.gov.br/inep/pt-br/areas-de-atuacao/ pesquisas-estatisticas-e indicadores/censo-da-educacao-superior. Acesso em: 12 jul. 2020.

PEREIRA, L. D. O ensino superior brasileiro privado-mercantil e a expansão via EaD no pós-2003: análise das matrículas em cursos de Serviço Social. In: PEREIRA, L. D.; ALMEIDA, N. L. T. de. Serviço Social e educação. Uberlândia: Editora Navegando, 2020.

SGUISSARDI, V. A educação superior e a crescente desigualdade social no Brasil em tempos ultraliberais. In: PEREIRA, L. D., BARBOZA, D. R. (Org.). Políticas regressivas e ataques aos direitos sociais no Brasil: dilemas atuais em um país de capitalismo dependente. Uberlândia: Editora Navegando, 2020.

VALE, A. A. do; PEREIRA, L. D. (Org.). O ensino a distância na formação em Serviço Social: análise de uma década. Rio de Janeiro: Editora E-Papers, 2019. Disponível em: http://www.e-papers.com.br/produtos.asp?codigo_ produto $=3123 \&$ promo=7. Acesso em: 7 jul. 2020.

DOI: $10.12957 /$ rep.2021.60307

Recebido em 12 de março de 2021.

Aprovado para publicação em 02 de abril de 2021.

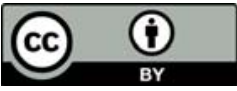

A Revista Em Pauta: Teoria Social e Realidade Contemporânea está licenciada com uma Licença Creative Commons Atribuição 4.0 Internacional. 